\title{
Allogeneic serum eye drops for the treatment of persistent corneal epithelial defect
}

\begin{abstract}
Purpose To evaluate the efficacy and safety of allogeneic serum in the treatment of persistent corneal epithelial defect (PED).

Methods Thirty-six patients with PED whose autologous serum was unavailable or unsuitable for use were included in the study. Blood was obtained from the patients' family members who were healthy and had no history of hepatitis, bacteremia, or HIV. After standard serological testing used in blood transfusion, the allogeneic serum was prepared. The patients applied the serum eyedrops once every hour while awake and discontinued non-preservative artificial tears. If the epithelial defect was healing, the allogenic serum was gradually tapered. If the epithelial defect remained nearly the same size at day 14, amniotic membrane transplantation (AMT) was performed.

Results Among the 36 patients, the epithelial defect healed in 6 patients (16.7\%) within 1 week, in an additional 9 patients (25\%) in 1-2 weeks, totaling 15 patients $(41.7 \%)$ within 2 weeks. Twenty-one patients $(58.3 \%)$ did not completely heal at the second week. Among these 21 patients, $10(27.8 \%)$ underwent AMT and had subsequent healing of the epithelial defect, 8 completely healed within 1 month, and the remaining 3 healed within 2 months. None of the 36 patients reported any adverse events during therapy.

Conclusions In patients for whom serum treatment is indicated but autologous serum is unavailable or unsuitable for use, allogeneic serum offers an alternative option for therapy. Eye (2009) 23, 290-293; doi:10.1038/sj.eye.6703079; published online 11 January 2008
\end{abstract}

The authors have no proprietary or financial interest in any material or device mentioned.
Keywords: allogeneic serum; corneal epithelial defect; autologous serum; dry eye
Introduction

Autologous serum eye drops have been indicated for the treatment of persistent corneal epithelial defect (PED) in several ocular surface disorders. ${ }^{1-6}$ Autologous serum has been found to contain vitamin $\mathrm{A}$, epidermal growth factor, fibronectin, and transforming growth factor- $\beta$, which are important substances for corneal and conjunctival integrity. ${ }^{3,4}$ However, autologous serum may be contraindicated or unavailable in infants, the elderly, patients with severe systemic bacterial infections or acute autoimmune disease, and those afraid of phlebotomy. In addition, in traditional Chinese/ Taiwanese culture, patients hesitate to have frequent venepuncture because they believe that this procedure will weaken them; this belief is especially common in the elderly. For those patients, ophthalmologists have sought a substitute for autologous serum that contains the above substances that are important in epithelial growth. Allogeneic serum has these same substances found in autologous serum. Furthermore, Tsubota et $a l^{5}$ found that even xenogeneic fetal calf serum enhanced human corneal epithelial migration in vitro. Hence, allogeneic serum may be an appropriate alternative for selected patients with PED who would benefit from serum treatment but whose autologous serum is unavailable or unsuitable.

In our clinical protocol, we use serum eye drops in patients with PED who have had no improvement with 2 weeks of conventional treatment, such as non-preservative artificial tears or extended wear soft contact lenses. For those patients, we usually replace artificial tears with autologous serum for another 2 weeks. Previously, patients who could not be treated with autologous serum underwent amniotic membrane transplantation (AMT). This 
prospective study was designed to evaluate the role of allogeneic serum in the treatment of PED.

\section{Materials and methods}

We defined PED as 'a corneal epithelial defect persisting more than 2 weeks, without improvement despite conventional treatment, such as non-preservative artificial tears or extended wear soft contact lenses'. This definition is the same as that used by Tsubota et al. ${ }^{5}$ Thirty-six eyes of 36 patients with PED whose autologous serum was unavailable or unsuitable for use were included. The original causes of the 36 patients were as follows: 15 patients were status post-penetrating keratoplasty, 10 had neurotrophic ulcers, 4 had chronic graft-versus-host disease (GVHD) with

keratoconjunctiva sicca syndrome, 4 had exposure keratopathy, 2 had chemical injuries, and 1 had status post-corneal ulcer. The initial treatment was nonpreservative artificial tears (Tears Naturale Free; Alcon Laboratories Inc., Fort Worth, TX, USA) and extended wear soft contact lenses in post-penetrating keratoplasty, neurotrophic ulcers, GVHD, chemical injuries and postcorneal ulcer, and non-preservative artificial tears and tarsorrhaphy in exposure keratopathy. There were nine post-penetrating keratoplasty and four neurotrophic ulcer patients ever underwent punctal occlusion. All the patients failed the conventional treatment. Their relatives' allogeneic serum was used as a substitute for artificial tears and usually taken from a spouse, a child, or a grandchild. The serum was first screened using standard tests in blood bank screening to check for blood-borne diseases human immunodeficiency virus, hepatitis $B$ virus, and hepatitis $C$ virus. The allogeneic serum was prepared by the following method: 20 or $40 \mathrm{ml}$ of peripheral blood was obtained from the donor using a sterile technique. Then the blood was centrifuged immediately at 1500 r.p.m. ( $239 \mathrm{~g}$ ) for $10 \mathrm{~min}$. The serum was dispensed without dilution into two or four $5 \mathrm{ml}$ plastic bottles and stored in a refrigerator at $4{ }^{\circ} \mathrm{C}$. The patients used the $100 \%$ allogeneic serum eye drops once every hour while awake and discontinued nonpreservative artificial tears. During the course of allogeneic serum eye drops, the therapeutic contact lens was not used. Because of the need to instil the serum drops frequently, the allogeneic serum had to be prepared every 2 weeks. This choice of 2 weeks for storage was based on a report by Tsubota et $a l^{1,5}$ that the levels of epidermal growth factor, transforming growth factor- $\alpha$, and vitamin A in $100 \%$ serum remained stable at $4{ }^{\circ} \mathrm{C}$ for at least 1 month. The patients were followed up on days $3,7,14,21,28$, and then every 2 weeks. If the epithelial defect was healing, the allogenic serum was gradually tapered. If on day 14 the epithelial defect remained nearly the same size as before the allogenic serum treatment, AMT was performed. The research followed the tenets of the Declaration of Helsinki, and informed consent was obtained from each patient and their family after counselling regarding the current hypothesis and possible complications, such as transmission of blood-borne diseases. The study was approved by the China Medical University Hospital institutional review board.

\section{Results}

The median follow-up period after treatment with allogeneic serum eye drops was 14.6 months (range 3-20 months). The original causes of the PEDs were shown in Table 1. Among the 36 patients, the epithelial defect healed in 6 patients $(16.7 \%)$ within 1 week and a total of 15 patients $(41.7 \%)$ within 2 weeks. Among these 21 patients who did not completely heal at the end of 2 weeks, $10(27.8 \%)$ had nearly the same size of epithelial defect before allogeneic serum treatment and underwent AMT with subsequent healing. Of the remaining 11 patients with partially healed PEDs at 2 weeks, 8 had complete healing within 1 month, and the remaining 3 had complete healing within 2 months. None of the 36 patients reported any adverse events during therapy.

Twenty-five patients used allogeneic serum prepared from genetic relatives, and 11 from non-consanguineous donors. In the group with genetically related donors, 17 $(68 \%)$ patients eventually responded to serum treatment and $8(32 \%)$ needed AMT; in the group with nonconsanguineous donors, $9(82 \%)$ patients responded to serum therapy and $2(18 \%)$ needed AMT. There was no significant difference in the response to treatment between patients treated with serum from genetic relatives and non-consanguineous donors in each round of experiments $(P=0.35)$.

\section{Discussion}

In vitro studies have shown that serum eye drops support viability, proliferation, and migration of ocular surface epithelial cells better than unpreserved pharmaceutical tear substitutes. ${ }^{5,6}$ Topical autologous serum drops are used clinically and have been found to be beneficial for severe dry eyes and PED. ${ }^{1,5-8}$ To our knowledge, no in vivo studies have been published on the use of allogeneic serum to treat PED. However, in vitro studies showed allogeneic ${ }^{6}$ and xenogeneic ${ }^{5}$ serum accelerated the migration and proliferation of human corneal epithelium.

In our patients, epithelial defects persisted or even progressed to impending corneal perforation despite frequent application of artificial tears. Pharmaceutical 
Table 1 Original disease and outcome of patients with PED

\begin{tabular}{|c|c|c|c|c|c|}
\hline Original disease $(\mathrm{n})$ & $\begin{array}{l}\text { Healed within } \\
1 \text { week, } \mathrm{n}(\%)\end{array}$ & $\begin{array}{c}\text { Healed within } \\
1-2 \text { weeks, } \mathrm{n}(\%)\end{array}$ & $\begin{array}{c}\text { Healed within } \\
2-4 \text { weeks, n (\%) }\end{array}$ & $\begin{array}{c}\text { Healed within } \\
1-2 \text { months, } \mathrm{n}(\%)\end{array}$ & $\begin{array}{l}A M T \\
\mathrm{n}(\%)\end{array}$ \\
\hline Post-PKP (15) & $3(20)$ & $4(26.7)$ & $2(13.3)$ & $1(6.7)$ & $5(33.3)$ \\
\hline Neurotrophic ulcer (10) & $0(0)$ & $2(20)$ & $3(30)$ & $2(20)$ & $3(30)$ \\
\hline GVHD (4) & $1(25)$ & $1(25)$ & $1(25)$ & $0(0)$ & $1(25)$ \\
\hline Exposure keratopathy (4) & $1(25)$ & $2(50)$ & $1(25)$ & $0(0)$ & $0(0)$ \\
\hline Chemical injury (2) & $0(0)$ & $0(0)$ & $1(50)$ & $0(0)$ & $1(50)$ \\
\hline Post corneal ulcer (1) & $1(100)$ & $0(0)$ & $0(0)$ & $0(0)$ & $0(0)$ \\
\hline Total (36) & $6(16.7)$ & $9(25)$ & $8(22.2)$ & $3(8.3)$ & $10(27.8)$ \\
\hline
\end{tabular}

AMT =amniotic membrane transplantation; $\mathrm{GVHD}=$ graft-versus-host disease; $\mathrm{PED}=$ persistent corneal epithelial defect; $\mathrm{PKP}=$ penetrating keratoplasty.

Table 2 PED healing time comparison

\begin{tabular}{lccccc}
\hline Healing within & $\begin{array}{c}\text { Current series } \\
(\mathrm{n}=36)(\%)\end{array}$ & $\begin{array}{c}\text { Young et al } \\
(\mathrm{n}=10)(\%)\end{array}$ & $\begin{array}{c}\text { Schulze et al } \\
(\mathrm{n}=13)(\%)\end{array}$ & $\begin{array}{c}\text { Poon et al }^{6} \\
(\mathrm{n}=15)(\%)\end{array}$ & $\begin{array}{c}\text { ssubota et al }^{5} \\
(\mathrm{n}=16)(\%)\end{array}$ \\
\hline 1 week & $6(16.7)$ & - & $12(92.3)$ & $3(20)$ & - \\
2 weeks & $9(25.0)$ & $6(60)$ & $1(7.7)$ & $-7(26.7)$ & $7(43.8)$ \\
1 month & $8(22.2)$ & $0(0)$ & $0(0)$ & $2(13.3)$ & $6(37.5)$ \\
$>1$ month & $3(8.3)$ & $2(20)$ & $0(0)$ & $0(0)$ & $0(0)$ \\
Default & $0(0)$ & $0(0)$ & $0(0)$ & $6(40)$ & $0(0)$ \\
Ineffective & $10(27.8)$ & $0(0)$ & & \\
\hline
\end{tabular}

$\mathrm{PED}=$ persistent corneal epithelial defect.

lubricants offer little to no nutrition. While autologous serum eye drops have tear-like biochemical characteristics and supply nutritional components, ${ }^{9}$ allogeneic serum can be used as an alternative in certain situations. In our study, the PED healed within 2 weeks in $41.7 \%(15 / 36)$ of the patients, within 4 weeks in $63.9 \%$ (23/36), and within 2 months in $72.2 \%$ (26/36). Table 2 summarizes the findings of our study and other studies on the treatment of PED with serum. Our results are comparable to these studies and corroborate the evidence that serum, either allogenic or autologous, is a safe and non-toxic agent. Schulze et al ${ }^{11}$ reported a higher healing rate in 13 patients (100\%) within 2 weeks. This response rate may be related to the fact that all the patients had corneal epithelial defects after pars plana vitrectomy for diabetic vitreoretinopathy without other predisposing ocular surface problems. Our patients may have been less likely to heal because their ocular conditions were more complicated (post-penetrating keratoplasty, GVHD-related dry eye, and neurotrophic keratopathy). These patients were initially scheduled to receive AMT, but were offered allogeneic serum as a medical option before surgical intervention. If the patients in our study had no response to therapy after 14 days, they underwent AMT to prevent further corneal stromal melting or infection. This cutoff time before resorting to surgery was shorter than that used in other studies and may explain the higher percentage of our patients who ultimately had surgery.
Owing to the possibility of transmitting blood-borne diseases, we recommend autologous serum as the best choice for PED when compared to pharmaceutical treatment. However, for patients without autologous serum available or suitable for use, allogeneic serum is an option. As blood transfusion has become widely accepted as a safe and effective therapy, using topical allogeneic serum eye drops is also ethical and legal. However, the risks of hypersensitivity reactions and the transmission of blood-borne diseases must be kept in mind. To minimize the risk of disease transmission, allogeneic blood must undergo the serological tests used in blood transfusions, including screening for human immunodeficiency virus, hepatitis B virus, and hepatitis $\mathrm{C}$ virus. Furthermore, a control system must be implemented to ensure that the product is only used when the microbiological and serological tests are clear. In our patients, allogeneic serum was obtained from family members who were healthy and had no history of hepatitis, bacteremia, or HIV, and the serum was tested before use. None of our patients developed systemic infections, microbial keratitis, or allergic reactions after instillation of allogeneic serum. We suggest young students and husbands are good donors if allogeneic serum is used.

AMT has been shown to be effective in the treatment of PED resistant to conventional medical therapy and autologous serum. ${ }^{11,12}$ Without allogeneic serum, the patients in our study would have undergone AMT due to 
a lack of response to conventional medical therapy coupled with the unavailability of autologous serum; however, only 10 of $36(27.8 \%)$ patients ultimately had AMT. Four of these had diabetes with herpetic keratitis, three had diabetes and were elderly, two had cranial nerve VII palsy with severe exposure keratopathy, and one had active GVHD with progressive corneal thinning. Vajpayee $e t a l^{13}$ reported that umbilical cord serum is an effective means of promoting epithelialization and can be safely used in PED. Both allogeneic blood serum eye drops and umbilical cord serum are allogeneic, but using the blood and serum from patients' spouses or young relatives is more convenient, more acceptable to patients and their families, and easily repeated for long-term use.

In clinical practice, autologous serum indeed poses fewer risks and is thus ethically preferable to allogeneic serum; as a result, allogeneic serum was only used in patients whose autologous serum was unavailable. Allogeneic serum, however, was found to promote the healing of PEDs refractory to non-preservative artificial tears and extended wear soft contact lenses and to decrease the frequency of AMT. Moreover, our results are comparable to other autologous studies in PED. ${ }^{5,6}$

In conclusion, allogeneic serum eye drops are safe and effective in treating PED. In patients who need serum treatment but whose autologous serum is unavailable or unsuitable for use, allogeneic serum offers a treatment alternative.

\section{References}

1 Tsubota K, Goto E, Fujita H, Ono M, Inoue H, Saito I et al. Treatment of dry eye by autologous serum application in Sjogren's syndrome. Br J Ophthalmol 1999; 83: 390-395.

2 Matsumoto Y, Dogru M, Goto E, Ohashi Y, Kojima T, Ishida $\mathrm{R}$ et al. Autologous serum application in the treatment of neurotrophic keratopathy. Ophthalmology 2004; 111: 1115-1120.

3 Ogawa Y, Okamoto S, Mori T, Yamada M, Mashima Y, Watanbe $\mathrm{R}$ et al. Autologous serum eye drops for the treatment of severe dry eye in patients with chronic graft-versus-host disease. Bone Marrow Transplant 2003; 31: 579-583.

4 van Setten GB, Viinikka L, Tervo T, Pesonen K, Tarkkanen A, Perheentupa J et al. Epidermal growth factor is a constant component of normal human tear fluid. Graefe's Arch Clin Exp Ophthalmol 1989; 227: 184-187.

5 Tsubota K, Goto E, Shimmura S, Shimazaki J. Treatment of persistent corneal epithelial defect by autologous serum application. Ophthalmology 1999; 106: 1984-1989.

6 Poon AC, Geerling G, Dart JK, Fraenkel GE, Daniels JT. Autologous serum eyedrops for dry eyes and epithelial defects: clinical and in vitro toxicity studies. $\mathrm{Br} J$ Ophthalmol 2001; 85: 1188-1197.

7 Fox RI, Chan R, Michelson J, Belmont JB, Michelson PE. Beneficial effect of artificial tears made with autologous serum in patients with keratoconjunctivitis sicca. Arthritis Rheum 1984; 29: 577-583.

8 Tseng SCG, Tsubota K. Important concepts for treating ocular surface and tear disorders. Am J Ophthalmol 1997; 124: 825-835.

9 Geerling G, Maclennan S, Hartwig D. Autologous serum eye drops for ocular surface disorders. Br J Ophthalmol 2004; 88: 1467-1474; review.

10 Young AL, Cheng AC, Ng HK, Cheng LL, Leung GY, Lam DS. The use of autologous serum tears in persistent corneal epithelial defects. Eye 2004; 18: 609-614.

11 Schulze SD, Sekundo W, Kroll P. Autologous serum for the treatment of corneal epithelial abrasions in diabetic patients undergoing vitrectomy. Am J Ophthalmol 2006; 142: 207-211.

12 Blanco AA, Pillai CT, Dua HS. Amniotic membrane transplantation for ocular surface reconstruction. $\mathrm{Br} J$ Ophthalmol 1999; 83: 399-402.

13 Vajpayee RB, Mukerji N, Tandon R, Sharma N, Pandey RM, Biswas NR et al. Evaluation of umbilical cord serum therapy for persistent corneal epithelial defects. Br J Ophthalmol 2003; 87: 1312-1316. 